Jurnal Kepelatihan Olahraga, Universitas Pendidikan Indonesia

\title{
Pengaruh Latihan Relaksasi Otot dengan Metode Progresif dan Autogenik terhadap Pemulihan Atlet Judo
}

\author{
Sopian $^{1 *}$, Ira Purnamasari ${ }^{1}$ \\ ${ }^{1}$ Pendidikan Kepelatihan Olahraga, Fakultas Pendidikan Olahraga dan Kesehatan, Universitas \\ Pendidikan Indonesia, Bandung, Indonesia \\ *Sopianjudo@gmail.com
}

\begin{abstract}
A B S T R A C T S
The aim of this study was to determine the effect of recovery of judo athletes with mental training using the method of Progressive Muscle Relaxation and Autogenic Relaxation. The research method used was the experimental method with one group pretest-posttest design, the population used was the Judo District West Bandung District Pelatcab athlete, totaling 10 people with total sampling technique. Measurement of pulse is carried out in the first 5 minutes, measured every minute. The results of the study of progressive and autogenic muscle relaxation exercises in the recovery of judo athletes produced a significant value. Therefore both methods are suitable given to judo athletes as recovery. However, muscle relaxation exercises using the Autogenic method are better than those with muscle relaxation exercises using the Progressive method.
\end{abstract}

C 2019 Tim Pengembang Jurnal Kepelatihan Olahraga
ARTICLE INFO

Article History:

Received 28 Feb 2019

Revised 4 March 2019

Accepted 11 March 2019

Available online 31 March 2019

Keyword:

Progressive Muscle Relaxation,

Autogenic Relaxation,

and Judo Athlete Recovery.

I NFO ARTIKE L

\section{Riwayat Artikel:}

Diterima 28 Feb 2019

Direvisi 4 Maret 2019

Diterima 11 Maret 2019

Tersedia online 31 Maret 2019

Kata Kunci:

Relaksasi Otot Progresif,

Relaksasi Autogenik,

dan Pemulihan Atlet Judo. 


\section{PENDAHULUAN}

Olahraga Judo terdiri dari dua suku kata yaitu $J U$ dan $D O, J U$ artinya lembut atau halus, $D O$ artinya cara atau jalan. Berarti, "Cara yang lembut atau jalan yang halus. Olahraga judo merupakan olahraga beladiri yang unik, karena gerakannya terlihat keras dan membahayakan, tapi sebenarnya tujuan dari olahraga tersebut bukan untuk menghancurkan lawan. Teknik judo terdiri dari teknik bantingan, kuncian, cekikan dan patahan.

Judo merupakan olahraga kompetitif yang memberikan kesempatan bagi atlet untuk menunjukan prestasi. Oleh karena itu, perlu adanya upaya dan usaha pengembangan melalui berbagai kegiatan pembinaan yang baik melalui latihan di klub-klub, maupun di perkumpulan lainnya, dalam meningkatkan prestasi atlet.

Prestasi tinggi dapat diperoleh melalui pembinaan yang tepat, serta usaha keras yang dari dalam diri seorang pejudo. Selain itu perlu ditunjang oleh kemampuan menguasai teknik, taktik, kondisi fisik yang prima, mental yang baik, kualitas pelatih yang didukung juga oleh sarana dan prasarana yang baik, serta disiplin ilmu yang erat tujuanya dengan olahraga. Selain itu ditunjang oleh program latihan yang direncanakan dengan baik, terarah, dan bermutu. Pelatih mengetahui bahwa, salah satu tujuan dan sasaran dari latihan adalah membantu atlet meningkatkan keterampilan dan prestasinya semaksimal mungkin. Program latihan yang dirancang oleh seorang pelatih tentu semakin hari semakin berat ketika mendekati jadwal pertandingan puncak. Seperti yang dijelaskan Harsono (2017, hlm. 50) bahwa, "Training adalah proses yang sistematis dari berlatih atau bekerja, yang dilakukan secara berulang-ulang, dengan kian hari kian menambah beban latihan atau pekerjaannya".

Fakta dilapangan para pelatih sering menggenjot atletnya dengan latihan berat dari mulai latihan fisik dan teknik tanpa memperhatikan pemberian recovery training. Padahal latihan pemulihan sangat diperlukan saat latihan maupun pertandingan, karena saat latihan atlet harus bisa menjalankan program latihan yang diberikan pelatih dengan maksimal. Latihan dengan densitas yang tinggi akan membuat atlet cepat lelah. Untuk dapat selalu bugar dalam latihan atlet perlu melatih kemampuan recovery nya saat latihan agar performanya kian hari kian meningkat sehingga peak performance akan tercapai.

Selama latihan dan kompetisi, sistem energi tubuh dapat menjadi lemah sebagai akibat banyaknya energi yang terpakai selama aktivitas fisik berlangsung. Apabila tubuh pulih dengan cepat, maka tubuh mampu melaksanakan beban latihan yang diprogramkan atau mencapai sasaran yang diharapkan. Prinsip pemulihan atau recovery sendiri menurut Harsono (2017, hlm. 90) adalah "Kalau kita ingin berprestasi maksimal, maka setelah tubuh diberi rangsangan (stimulus), harus ada Complete Recovery (pulih asal) sebelum pemberian stimulus berikutnya, latihan tanpa recovery yang cukup tak akan banyak manfaatnya bagi atlet". Lamanya recovery tergantung dari tingkat kelelahan yang dirasakan atlet dari rangsangan latihan sebelumnya. Makin sedikit kelelahan yang dialaminya, makin sedikit pula waktu yang diperlukan untuk proses pemulihan. Sebaliknya, makin tinggi kelelahan yang dideritanya, makin 
lama pula waktu istirahat yang diperlukan untuk pemulihan.

Metode pemulihan yang saat ini yang banyak digunakan oleh club-club judo adalah pemulihan secara pasif. Metode pemulihan atlet judo bisa dilakukan dengan latihan keterampilan mental berupa teknik relaksasi untuk mendongkrak performanya, ini lebih efektif daripada metode pemulihan secara pasif berupa peregangan dinamis atau statis. Seperti yang diungkapkan Greenspan \& Felz (1989) (dalam Komarudin, 2015, hlm. 20) mengatakan bahawa "Latihan keterampilan mental sangat efektif untuk meningkatkan performa atlet". Namun para pelatih banyak yang tidak mengetahui teknik-teknik relaksasi apa saja yang harus dilatih.

Ada beberapa teknik latihan relaksasi sebagai pemulihan untuk atlet seperti Harsono mengungkapkan (1998, hlm. 283) bahwa, "Latihan relaksasi diantaranya adalah teknik progressive muscle relaxation, teknik autogenic relaxation". Latihan dengan metode latihan relaksasi progresif menurut Setyobroto (dalam Komarudin, 2015, hlm. 101) adalah latihan yang dilakukan dengan cara menegangkan otot-otot pada seluruh tubuh sebelum mebuat otot-otot tersebut relaks. Metode latihan relaksasi ini harus disusun secara sistematis mulai dari otot bagian atas sampai otot bagian bawah pada tubuh. Beberapa manfaat teknik latihan dengan metode latihan relaksasi progresif (2010) adalah, menurunkan ketegangan otot, kecemasan, nyeri leher dan punggung, tekanan darah tinggi, frekuensi jantung, dan laju metabolic.
Selain latihan dengan metode latihan relaksasi progresif ada juga yang disebut dengan metode latihan relaksasi autogenic. Menurut Widiastuti (2015, hlm. 285), Autogenic training lebih menekankan pada self-sugestion atau pemberian sugesti kepada diri sendiri”. Maka latihan ini mensugestikan diri atlet dalam beberapa perasaan. Bentuk latihan relaksasi yang secara sistematis memikirkan dan merasakan bagian tubuh sebagian hangat dan terasa berat. Latihan ini dapat dilakukan setelah atlet selesai melakukan semua aktivitas latihan supaya atlet dapat memulihkan kebugarannya dengan cepat dan merasa relaks (Lilik 2007).

Saat persiapan menghadapi pertandingan judo merupakan situasi yang dapat menimbulkan anxiety, disebabkan karena pengaruh teriakan penonton, melihat kemampuan lawan, atau keadaan sekitar. Kondisi ini dapat menyebabkan atlet terpengaruh dan merasa tertekan, dan pada akhirnya akan membuat atlet kurang berkonsentrasi pada saat pertandingan. Dalam situasi tersebut atlet harus menekan tingkat ketegangan dan memiliki kesiapan mental sehingga dapat bermain dengan baik tanpa terpengaruh oleh keadaan sekitarnya. Untuk memiliki kemampuan tersebut diperlukan latihan untuk mengontrol emosi dan besikap relaks. Oleh karena itu peneliti ingin mengetahui pengaruh latihan relaksasi dengan metoda Progressive Muscle Relaxation dan Autogenic Relaxation pada atlet judo.

\section{METODE}


Penelitian ini menggunakan metode eksperimen dengan desain penelitian one groups pretest-posttest.

Teknik pengambilan sampel dalam penelitian ini adalah total sampling. Program latihan (treatment) ini diberikan selama selama 4 minggu dengan total 16 kali pertemuan. 4 kali/minggu. Pemeriksaan nadi dilakukan dengan metoda palpasi pada pergelangan tangan selama 5 menit yaitu P1 P2 P3 P4 P5 setiap denyut nadi dihitung penurunannya per menit. P1 adalah denyut nadi per 30 detik terakhir dari menit ke-1 pada pemulihan; P2 adalah denyut nadi per 30 detik terakhir dari menit ke-2 pada pemulihan; P3 adalah denyut nadi per 30 detik terakhir dari menit ke-3 pada pemulihan; P4 adalah denyut nadi per 30 detik terakhir dari menit ke-4 pada pemulihan; P5 adalah denyut nadi per 30 detik terakhir dari menit ke-5 pada pemulihan. Berikutnya, nilai yang digunakan dalam penelitian ini adalah nilai selisih P1 dan P5.

\subsection{Subjek Penelitian}

Populasi dalam penelitian ini adalah seluruh atlet Pelatcab Judo Kabupaten Bandung Barat yang berjumlah 10 orang. Subjek penelitian adalah seluruh atlet Pelatcab Judo Kabupaten Bandung Barat yang berjumlah 10 orang.

\subsection{Prosedur Penelitian}

Tahapan penelitian yang dilakukan adalah sebagai berikut: (1) Melakukan test awal (pre-test) (2) Setelah itu data test diranking. (3) Setelah data tersusun, sampel dibagi menjadi 2 kelompok. (4) Melakukan perlakuan (treatment) untuk kelompok A dengan menggunakan metode latihan relaksasi progresif muscle relaxation, dan B menggunakan metode relaksasi autogenic relaxation. (5) Masing-masing kelompok menjalani kegiatan eksperimen selama waktu yang telah ditetapkan. (6) Setelah menjalani perlakuan (treatment) kemudian lakukan test akhir (post-test). (7) Setelah memperoleh data awal dan akhir, kemudian diolah dan dianalisis secara statistik sehingga hasilnya dapat ditafsirkan dan dijadikan acuan dalam pengambilan kesimpulan.

\section{HASIL PENELITIAN}

Hasil Perhitungan dan Uji signifikansi dapat dilihat pada Tabel 3.1.

Tabel 3.1 Paired Sample Test

\begin{tabular}{cccc}
\hline Kelompok & $\mathrm{t}$ hitung & $\mathrm{t}$ tabel & Signifikansi \\
\hline Otot Progresif & 3,674 & 2,776 & Signifikan \\
\hline Autogenik & 5,880 & 2,776 & Signifikan \\
\hline
\end{tabular}


Berdasarkan data diatas penulis keinginan untuk meningkatkan sering menggunakan Uji T Paired pada kelompok A mengakibatkan overtraining. Jika otot tidak dan kelompok B untuk mengetahui signifikan atau tidaknya data. Setelah dilakukan uji signifikansi diketahui $\mathrm{T}$ hitung dari kelompok A sebesar 3,674 dengan df 4 pada taraf $\alpha$ 0,05 maka $\mathrm{T}$ tabel $=2,776$ maka $\mathrm{T}$ hitung kelompok $\mathrm{A}$ $3,674>2,776$ yang berarti terdapat pengaruh yang signifikan. Sedangkan pada kelompok B T hitung sebesar 5,880 dengan df 4 pada taraf $\alpha$ 0,05 maka $\mathrm{T}$ tabel $=2,776$ maka $\mathrm{T}$ hitung kelompok B 5,880 > 2,776 yang berarti terdapat pengaruh yang signifikan pada kelompok B. Lihat Grafik 3.1.

Grafik 3.1. Perbandingan pre-test dan post-test kelompok latihan relaksasi otot progresif.

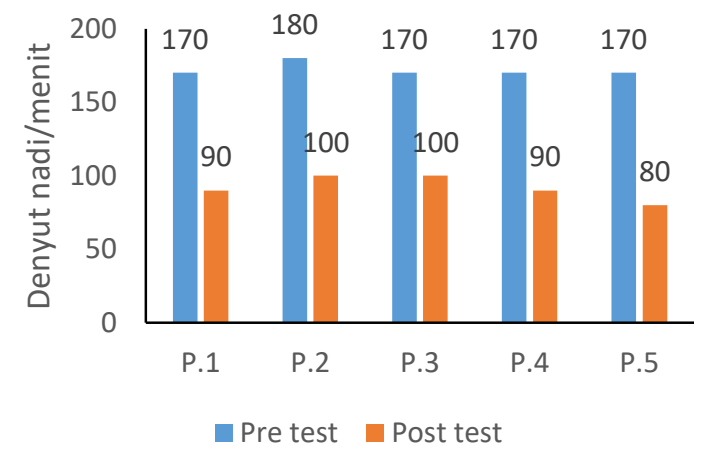

Grafik 3.1 menggambarkan grafik perbedaan penurunan denyut nadi pemulihan (DN5) pada saat pre-test dan post-test pada kelompok latihan relaksasi otot progresif.

Banyak atlet berlatih terlalu keras dan terlalu lama dengan tidak memperhatikan kemampuan dirinya sesuai dengan kebutuhan latihan, sehingga dapat menyebabkan overtraining. Hal ini bisa terjadi ketika otot tidak diberi waktu untuk recovery atau pemulihan yang diperlukan. Semua orang ingin berada dipuncak pada saat kompetisi, sayangnya

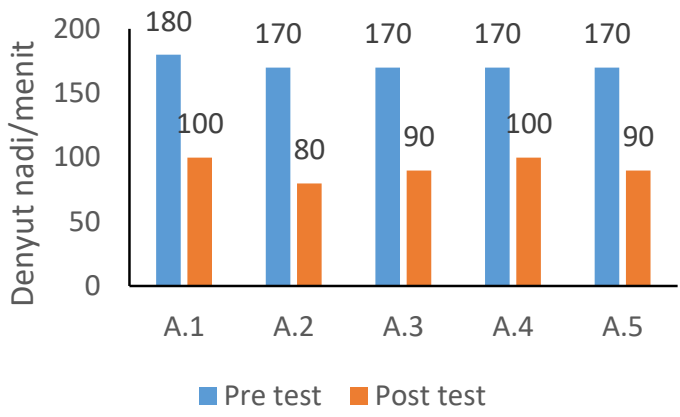

mendapatkan waktu pemulihan (recovery) yang cukup, mereka tidak akan kembali kuat (overtraining), dan bisa saja berakibat fatal bagi seorang atlet yaitu dapat menyebabkan cedera.

Dari data tersebut dapat disimpulkan bahwa, setelah melakukan treatment relaksasi otot secara progresif, sampel mengalami peningkatan penurunan denyut nadi pemulihan.

Grafik 3.2. Perbandingan pre-test dan post-test kelompok latihan relaksasi autogenik.

Grafik 3.2 menggambarkan bahwa, perbedaan penurunan denyut nadi pemulihan (DN5) pada saat pre-test dan post-test pada kelompok latihan relaksasi autogenik. Selanjutnya, dari data tersebut dapat disimpulkan bahwa setelah melakukan treatment relaksasi autogenik, sampel mengalami perbedaan penurunan denyut nadi pemulihan pada saat pretest dan posttest.

\section{PEMBAHASAN}

Dari data yang diperoleh dari hasil pretest dan posttest dapat dibandingkan hasilnya bahwa, latihan relaksasi otot progresif dan autogenik 
memberikan pengaruh yang signifikan pada pemulihan atlet judo.

Teknik-teknik latihan relaksasi ini mungkin saja bisa menjadi cara bagi seorang pejudo untuk menghadapi situasi cemas sehingga ia menjadi relaks kembali dengan cepat. Selain itu teknik relaksasi ini bisa juga dipakai untuk memulihkan badan saat melakukan rentetan stimulus latihan atau sebagai cara cooling down. Pemulihan relaksasi memiliki peran untuk menenangkan diri secara psikologis serta menghilangkan asam laktat yang ada dalam darah dan otot tubuh, karena asam laktat adalah produksi sisa sementara yang menghambat pergerakan dan koordinasi kerja otot sehingga seseorang menjadi cepat lelah. Oleh karena itu diperlukan cara pengurangan asam laktat dengan memasukkan oksigen (O2) untuk mengoksidasi serta mengemilinir asam laktat yang menumpuk.

Pada penelitian ini dilakukan pengukuran denyut nadi pemulihan yang bertujuan untu penanda tingkat kebugaran fisik atlet. Relaksasi tidak hanya sebagai teknik untuk membuat atlet dalam keadaan relaks dan menstabilkan emosi saja, tetapi juga sebagai strategi agar atlet pulih kembali dengan cepat saat bertanding agar performanya maksimal. Seperti yang diungkapkan oleh Singgih (1987) (dalam Komarudin, 2015, hlm. 101) bahwa, "Tujuan latihan relaksasi adalah agar atlet bisa dengan cepat menjadi relaks kalau dibutuhkan". Oleh sebab itu, latihan relaksasi harus dipelajari dan dilatihkan oleh pelatih kepada atletnya agar dapat mengontrol diri memfokuskan perhatian sehingga dapat mengambil respon yang tepat saat berada dalam situasi yang menegangkan. Relaksasi dapat membantu menghilangkan gejala stress meskipun penyebab kecemasan tidak akan menghilang, sehingga akan merasakan kembali mampu menghadapinya setelah merilis ketegangan di tubuh dan membersihkan pikiran. Pemulihan ini bisa dilihat dari deyut nadi pemulihan atlet bisa mencapai batas normal pada menit ke 5. Selain itu alasan kenapa latihan relaksasi bisa memulihkan denyut nadi didukung oleh teori yang diungkapkan oleh Smeltzer \& Bare (dalam Sherwood, 2011) bahwa, "Pada saat relaksasi juga sekresi CRH (cotricotropin releasing hormone dan ACTH (adrenocorticotro pic hormone) di hipotalamus menurun".

Penurunan kedua sekresi hormon ini menyebabkan aktivitas syaraf simpatis menurun sehingga pengeluaran adrenalin dan noradrenalin berkurang, akibatnya terjadi penurunan denyut jantung, pembuluh darah melebar, tahanan pembuluh darah berkurang dan penurunan pompa jantung sehingga tekanan darah arterial jantung menurun.

\section{KESIMPULAN DAN SARAN}

Berdasarkan hasil pengolahan dan analisis data, maka kesimpulan dari penelitian Pengaruh Latihan Relaksasi Otot dengan Metode Progresif dan Autogenik Terhadap Pemulihan Atlet Judo adalah sebagai berikut : (1) Terdapat pengaruh yang signifikan pada metode latihan relaksasi otot progresif terhadap pemulihan atlet judo. (2) Terdapat pengaruh yang signifikan pada metode latihan relaksasi autogenik terhadap pemulihan atlet judo.

Atas dasar hasil dari penelitian ini, maka saran yang dapat dikemukakan adalah sebagai berikut : (1) Bagi pembaca dan pelatih olahraga judo untuk memberikan latihan keterampilan 
mental dengan teknik relaksasi kepada atletnya untuk memulihkan performa atlet. (2) Pelatih dapat menerapkan kedua metode relaksasi tersebut, meskipun demikian untuk hasil latihan relaksasi otot menggunakan metode Autogenik lebih baik dibandingkan dengan latihan relaksasi otot menggunakan metode Progresif.
Berkaitan dengan penelitian yang penulis lakukan, sebaiknya diadakan penelitian lebih lanjut dengan metode berbeda pada penelitian ini.

\section{DAFTAR PUSTAKA}

Achmad,A.K.A. (2013) Olahraga Judo. Bandung: Rosda

Benson, H dan Kliper, M. (2000) Pengaruh Meditasi terhadap Kestabilan Emosi Siswa SMU. Other thesis, Unika.[Online]. Diakses dari : http://eprints.unika.ac.id/834/

Bernstein, P.A and Borkovec, T.D (1973). Progresive Muscle relaxation Training, A manual for the Helping Proffesions, Illinois: Research Press. [Online]. Diakses dari : http://eprints.ums.ac.id

Dewi, Ni Ketut. (2018). Sport and Fitness Journal [Online]. Diakses dari: http://sinta.unud.ac.id

Dimas Vironika. (2012) . Relaksasi Otot Progresif dan Terapi Tertawa Untuk Menurunkan Tekanan

Darah Hipertensi. [Online]. Diakses di : https:/studylibid.com/doc/273524/relaksasi-ototprogresif-dan-terapi-tertawa-untuk-menurunkan

Edward R. Laskowski, M. D. (2000). Physical Medicine and Rehabilitation Specialist. Oxford.

Fraenkel, Jack R dan Wallen, Norman E. (2012). How to Design and Avaluate Research in Education (sixth edition). New York: McGraw-Hill Companies.

Harsono. (1988). Coaching : Aspek-aspek Psikologis Dalam Coaching. Jakarta: CV Tambak Kusuma. Harsono. (2017). Kepelatihan Olahraga Teori dan Metodologi. Bandung: PT. Remaja Rosdakarya.

Hartono, Widiyanto, Suprijanto. (2012). Recovery Oksigen Perubahan Kadar Asam Laktat Darah dan Performa Anaerobik Setelah Hiperbarik dan Recovery aktif.

Herodes. (2010). Teknik Relaksasi Progresif Terhadap Insomnia Pada Lansia. [Online]. Diakses dari: :http://herodessolution.blogspot.com/2010/11/teknik-relaksasi-progresif -terhadap.

Herodes. (2010). Teknik Relaksasi Progresif Terhadap Insomnia Pada Lansia. [Online]. Diakses dari: http://herodessolution.blogspot.com/2010/11/teknik-relaksasi-progresif.

Hidayat, Yusuf. (2008). Psikologi Olahraga. Bandung: Universitas Pendidikan Indonesia.

Ibrahim, Rusli dan Komarudin. (2008). Psikologi Olahraga. Bandung: FPOK/UPI Bandung. Infokes/article/v iew/127/123

Istiana Nurcahyani. (2016). Efektivitas Teknik Relaksasi dalam Konseling Kelompok Behavioral Untuk Menurunkan Stress Belajar Siswa SMA. [Online]. Diakses dari: http://journal2.um.ac.id

Jhones, M.Rhonda. (2008). Pattient Assessment in Pharmacy Practice. 2 ed. Publisher: Lippincott Williams \& wilkins.

Jigoro, Kano. (1989). Ilustrated Kodokan Judo. Japan. Kodansha International Ltd. 
Kamus Besar Bahasa Indonesia. [Online]. Diakses dari: http:/kbbi.web.id

Komarudin. (2015). Psikologi Olahraga Latihan Keterampilan Mental dalam Olahraga Kompetitif. Bandung: PT. Remaja Rosdakarya.

Lichstein. A. (1988). Development Theory of Konseing. Jakarta: Rineka Cipta.

Lilik, Sudarwati, Adisasmito. (2007) Mental Juara Modal Atlet Berprestasi. Jakarta: PT. RajaGrafindo Persada.

Lutan, Rusli, Berliana dan Sunaryadi. (2007). Penelitian Pendidikan Dalam Olahraga. Bandung: Jurusan Pendidikan Kepelatihan FPOK-UPI.

M. Noors (1998). Dasar- dasar Judo. Jakarta: Dian Rakyat.

Maksum, Ali. (2012). Metode Penelitian Dalam Olahraga. Semarang: UNESA University Press.

Pernafasan Dalam.[Online]. Diakses dari: https://www.apikescm.ac.id/ejurnalinfokes/index.php/

Ramdani, N., \& Putra, A. A. (2009) Pengembangan Multimedia Relaksasi. Jurnal Psikologi Volume 34 no.2. [Online]. Diakses dari : http://www.pzikologizone.com/langkah-langkah -relaksasiotot-progresif.

Rice, L.P (1999). Stress and health . California: Brooks/cole Publishing Company. [Online]. Diakses dari : https://www.researchgate.net.

Sadigh, M. R. (2001). Autogenic Training. A mind-body approach. New York : Haworth Medical Press. [Online]. Diakses dari: https://journal.ugm.ac.id.

Satiadarma, M.P (2000). Dasar-dasar Psikologi Olahraga. Jakarta: Pustaka Sinar Harapan

Setyo, Purwanto. (2006) Relaksasi Dzikir, [Online]. Diakses dari: http://scholar.google.co.id

Sherwood, Laura lee. (2011). Fisiologi Manusia. Jakarta: EGC.

Straub, W.F. (1980) Sport Psychology : An Analysis of Athlete Behaviour. 2nd ed.) Ithaca, N.Y.: Mouvement Publications. [Online]. Diakses dari : http://www.journal.ugm.ac.id

Sugiyono. (2016). Metode Penelitian Kuantitatif. Kualitatif. dan R\&D. Bandung: Alfabeta.

Syaodih. (2012). Metode Penelitian Pendidikan. Bandung: PT. Remaja Rosdakarya.

Tummers, Nenette. (2013). Stress Management. United States: Human Kinetics

Universitas Pendidikan Indonesia. (2016) Pedoman Penulisan Karya Ilmiah Bandung : UPI

Widiastuti. (2015). Tes dan Pengukuran Olahraga. Jakarta: PT. Raja Grafindo Persada.

Zuriah, Nurul. (2005). Metodologi Penelitian Sosial dan Pendidikan. Jakarta: Bumi Aksara. 
9 | Jurnal Kepelatihan Olahraga, Volume 11 No. 1, March 2019

Lampiran 1.

Prosedur Program Latihan Progresif Muscle Relaxation

\begin{tabular}{|c|c|c|c|}
\hline Minggu & Treatment & Waktu & Instruksi \\
\hline \multirow{27}{*}{$\begin{array}{l}\text { Minggu } \\
\text { Ke } 1-4\end{array}$} & \multicolumn{3}{|c|}{ Tahap Awal } \\
\hline & Duduk Rileks & \multirow{2}{*}{5 menit } & \multirow{2}{*}{$\begin{array}{l}\text { Kaki menyentuh lantai Pernafasan } \\
\text { dalam dengan formula 6"-2"-7" }\end{array}$} \\
\hline & Deep Breathing & & \\
\hline & \multicolumn{3}{|c|}{ Kegiatan Inti } \\
\hline & 1. Otot Wajah & \multirow{21}{*}{10 Menit } & \multirow{5}{*}{$\begin{array}{l}\text { Menegangkan otot secara isometrik } \\
\text { ditahan 5" }\end{array}$} \\
\hline & Dahi & & \\
\hline & Mata & & \\
\hline & Lidah & & \\
\hline & Mulut & & \\
\hline & 1. Otot Bahu dan leher & & \multirow[t]{4}{*}{ Relaksasi ditahan selama 10"-15" } \\
\hline & Bahu & & \\
\hline & Leher & & \\
\hline & Leher \& Dagu & & \\
\hline & 2. Otot Lengan & & \multirow{4}{*}{$\begin{array}{l}\text { Pusatkan perhatian pada otot yang } \\
\text { relasks }\end{array}$} \\
\hline & Lengan Kanan \& Kiri & & \\
\hline & Pergelangan Tangan & & \\
\hline & Lengan Atas & & \\
\hline & 3. Otot Dada & & \\
\hline & Dada & & \\
\hline & Perut & & \\
\hline & Punggung & & \\
\hline & 4. Otot Tungkai & & \\
\hline & Tungkai Belakang & & \\
\hline & Betis & & \\
\hline & Kaki & & \\
\hline & \multicolumn{3}{|c|}{ Penutup } \\
\hline & Evaluasi & 5 Menit & Instruksi \& Saran \\
\hline
\end{tabular}


Prosedur Program Latihan Relaksasi Autogenik

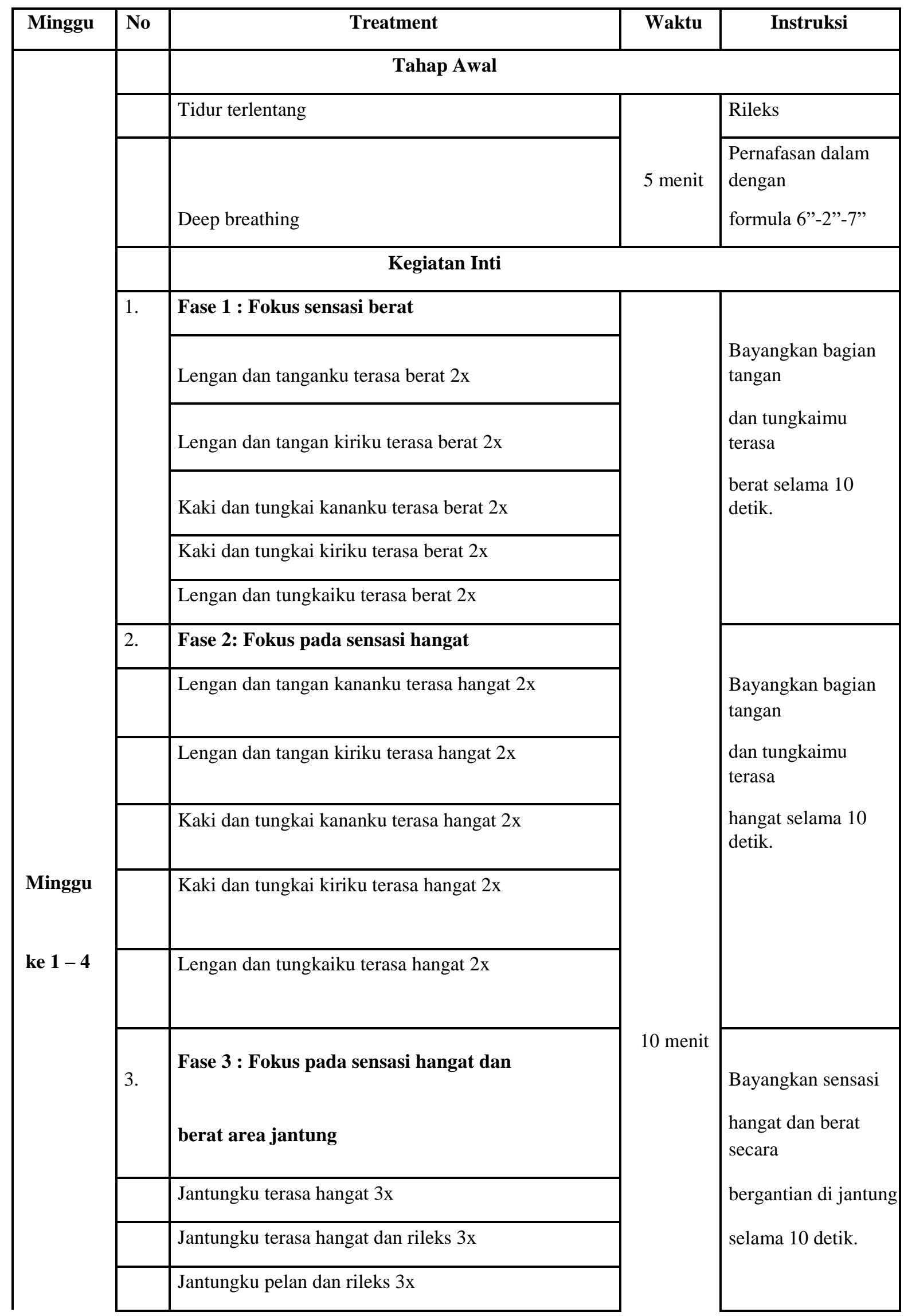


11 | Jurnal Kepelatihan Olahraga, Volume 11 No. 1, March 2019

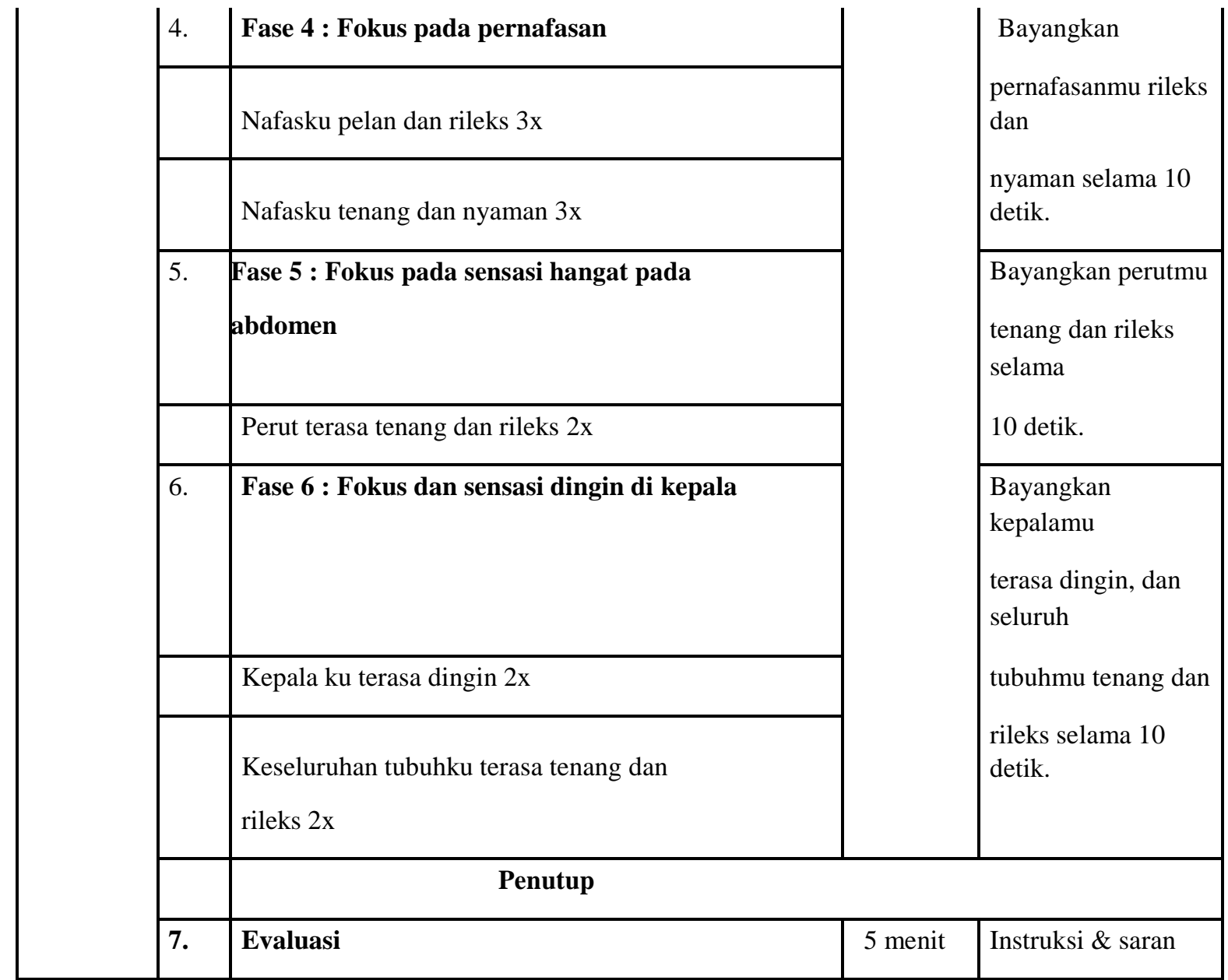

